\title{
Trends of non-methane hydrocarbons (NMHC) emissions in Beijing during 2002-2013
}

\author{
M. Wang ${ }^{1}$, M. Shao ${ }^{1}$, W. Chen ${ }^{1}$, S. Lu ${ }^{1}$, Y. Liu ${ }^{1}$, B. Yuan ${ }^{1, *}$, Q. Zhang ${ }^{1}$, Q. Zhang ${ }^{2}$, C.-C. Chang ${ }^{3}$, B. Wang ${ }^{1}$, L. Zeng ${ }^{1}$, \\ M. $\mathrm{Hu}^{1}$, Y. Yang ${ }^{1}$, and $\mathrm{Y} . \mathrm{Li}^{1}$ \\ ${ }^{1}$ State Joint Key Laboratory of Environmental Simulation and Pollution Control, \\ College of Environmental Sciences and Engineering, Peking University, Beijing, China \\ ${ }^{2}$ Ministry of Education Key Laboratory for Earth System Modeling, \\ Center for Earth System Science, Tsinghua University, Beijing, China \\ ${ }^{3}$ Research Center for Environmental Change, Academia Sinica, Taipei 115, Taiwan \\ *now at: NOAA Earth System Research Laboratory and Cooperative Institute \\ for Research in Environmental Sciences, University of Colorado, Boulder, CO, USA
}

Correspondence to: M. Shao (mshao@pku.edu.cn)

Received: 23 June 2014 - Published in Atmos. Chem. Phys. Discuss.: 21 July 2014

Revised: 29 December 2014 - Accepted: 16 January 2015 - Published: 11 February 2015

\begin{abstract}
Non-methane hydrocarbons (NMHCs) play a critical role in the photochemical production of ozone $\left(\mathrm{O}_{3}\right)$ and organic aerosols. Obtaining an accurate understanding on temporal trends of NMHC emissions is essential for predicting air quality changes and evaluating the effectiveness of current control measures. In this study, we evaluated temporal trends of anthropogenic NMHC emissions during August in Beijing based on ambient measurements during selected summer periods at an urban site in Beijing from 2002 to 2013. In the contrast to the results from the most recent inventory (Multi-resolution Emission Inventory for China, MEIC), which reported that anthropogenic NMHC emissions during August increased by $28 \%$ from 2004 to 2012, whereas mixing ratios of NMHCs measured at this urban site decreased by $37 \%$ during the same time period. A positive matrix factorization (PMF) model was applied to these NMHC measurements for source apportionment. The results showed that the relative contributions of vehicular exhaust and gasoline evaporation to measured NMHC concentrations decreased by $66 \%$ during August from 2004 to 2012, comparable to the relative decline of $67 \%$ for transportationrelated NMHC emissions reported by the MEIC inventory. This finding indicates that the implementation of stricter emissions standards for new vehicles and specific control measures for in-use vehicles has been effective for reducing transportation-related NMHC emissions. In addition, the
\end{abstract}

PMF results suggested that there were no significant temporal changes in NMHC concentrations from solvent use and industry during August from 2004 to 2012, in contrast with the rapid rate of increase $\left(8.8 \% \mathrm{yr}^{-1}\right)$ reported by the MEIC inventory. To re-evaluate the NMHC emissions trends for solvent use and industry, annual variations in $\mathrm{NMHC} / \mathrm{NO}_{\mathrm{x}}$ ratios were compared between ambient measurements at the PKU site and the MEIC inventory. In contrast to the significant rise in $\mathrm{NMHC} / \mathrm{NO}_{\mathrm{x}}$ ratios from the MEIC inventory, the measured $\mathrm{NMHC} / \mathrm{NO}_{\mathrm{x}}$ ratios declined by $14 \%$ during August from 2005 to 2012. The inferred $\mathrm{NMHC} / \mathrm{NO}_{\mathrm{x}}$ ratios based on PMF results exhibited a comparable decline of $11 \%$ to measured ratios. These results indicate that the increase rate for NMHC emissions from solvent use and industry in Beijing might be overestimated in the current inventory; therefore, additional research is necessary to verify the NMHC emission trends for this source.

\section{Introduction}

The temporal trends in tropospheric ozone $\left(\mathrm{O}_{3}\right)$ levels has been of great concern during recent years. Over the past three decades, significant declines in $\mathrm{O}_{3}$ levels have been observed in urban areas of the United States (US; Lefohn et al., 2010; Warneke et al., 2012). However, recent studies 
have suggested that $\mathrm{O}_{3}$ levels in China have been increasing (Wang et al., 2009; Zhang et al., 2014). Non-methane hydrocarbons (NMHCs) and nitrogen oxides $\left(\mathrm{NO}_{\mathrm{x}}\right)$ are precursors of photochemically produced $\mathrm{O}_{3}$; therefore, obtaining accurate knowledge on temporal trends in NMHC emissions is helpful for understanding $\mathrm{O}_{3}$ trends in urban regions (von Schneidemesser et al., 2014; Zhang et al., 2014).

One approach to investigating trends in NMHC emissions is based on emissions inventories, which are established by summing the products of activity data (A) and emission factors (EFs) for various sources (Bo et al., 2008; Lei et al., 2011b). Owing to the complexity of NMHC sources and the lack of local emission characteristic databases, large inherent uncertainties are expected for NMHC emission inventories in China. Several studies that evaluated NMHC emissions inventories in Beijing based on ambient measurements identified large uncertainties in the estimates, speciation, spatial distribution, and sources of NMHC emissions (Tang et al., 2011; Liu et al., 2012; Wang et al., 2014a). However, temporal trends for NMHC emissions in Beijing have not been evaluated using ambient measurements so far.

During the past decade, there has been a rapid increase in energy consumption in Beijing. Meanwhile, various control measures have been implemented to reduce anthropogenic emissions of NMHCs, such as the implementation of stricter emission standards for new vehicles, the elimination of heavy-polluting in-use vehicles, improvements in fuel quality, the installation of gasoline vapor recovery systems at gas stations, and restrictions on NMHC fractions in paint and solvents (Wei et al., 2011; Wang and Hao, 2012). The implementation of these control measures is helpful for reducing NMHC emission factors of stationary sources, vehicular exhaust, gasoline vaporization, and paint and solvent utilization. It is a challenge to obtain an accurate understanding on NMHC emission trends in Beijing due to the interaction between decreasing NMHC emission factors and increasing energy consumption.

Due to the large uncertainties in current emissions inventories, trend analysis on ambient measurements of NMHCs during long time periods is another important method for investigating the emissions trends of NMHCs and evaluating the accuracy of emissions inventories. Parrish (2006) used NMHC measurement data from 1975 to 2005 to evaluate critically emissions inventories for US on-road vehicles, and found that the temporal trends for NMHC emissions estimates and speciation were not consistent with ambient measurements. In China, only a few studies have reported temporal changes in ambient NMHC levels. Wang et al. (2012) measured NMHC levels at an urban site in Beijing from 2000 to 2007, and found that NMHC levels during summer increased from 2000 to 2003 and decreased from 2003 to 2007. Zhang et al. (2014) found that the mixing ratios of most anthropogenic NMHC species during August at another urban site in Beijing significantly decreased from 2005 to 2011. While these studies provide useful information about NMHC trends in Beijing, their results have not been used to evaluate the accuracy of NMHC emissions trends in current inventories and to examine the effectiveness of NMHC control measures.

In the present study, we evaluated the accuracy of NMHC emissions trends in Beijing based on ambient NMHC measurements collected during the summer at an urban site in Beijing from 2002 to 2013. We first introduced the temporal changes in anthropogenic NMHC emissions during August in Beijing reported by the multi-resolution emission inventory for China (MEIC). Temporal trends in ambient levels of NMHCs during summer from 2002 to 2013 were then analyzed using a simple linear regression method and were compared with NMHC emission trends reported by the MEIC inventory. A positive matrix factorization (PMF) model was applied to these NMHC measurement data for source apportionment to investigate temporal changes in NMHC concentrations from major sources. Finally, we compared the temporal changes in ratios of $\mathrm{NMHC}$ to $\mathrm{NO}_{\mathrm{x}}$ between ambient measurements and the MEIC inventory to re-evaluate the NMHC emission trends from solvent use and industry sources.

\section{Materials and methods}

\subsection{Anthropogenic NMHC emissions inventory}

Anthropogenic NMHC emissions during August in Beijing from 2002 to 2012 were obtained from the Multiresolution Emission Inventory for China (MEIC) (http:// www.meicmodel.org). This inventory was developed by a group at Tsinghua University in China that used a dynamic, technology-based methodology to estimate anthropogenic emissions in China from 1990 to 2012 (Zhang et al., 2009; Lei et al., 2011a; He, 2012; Li et al., 2014). Anthropogenic NMHC emissions were estimated using detailed activity data and local emission factors in China, and were categorized into five sources: transportation, industry, solvent use, residential activities, and power plants (Figs. 1 and 2). Details about the methodology that was used to establish the NMHC emission inventory can be found in Zhang et al. (2009) and Li et al. (2014).

\subsection{NMHC measurements}

Ambient measurements of NMHCs were conducted during summer at the same urban site in Beijing from 2002 to 2013. This site was located at a six-story building on campus of Peking University (PKU, $40.00^{\circ} \mathrm{E}, 116.31^{\circ} \mathrm{E}$ ) in the northwest of Beijing, which is about $200 \mathrm{~m}$ north of the FourthRing Road with high traffic density and is distant from industrial or agricultural sources. This site was considered to be representative of a typical urban environment in Beijing (Song et al., 2007; Zhang et al., 2014). Details about the analysis systems of NMHCs, measurement periods, and related 

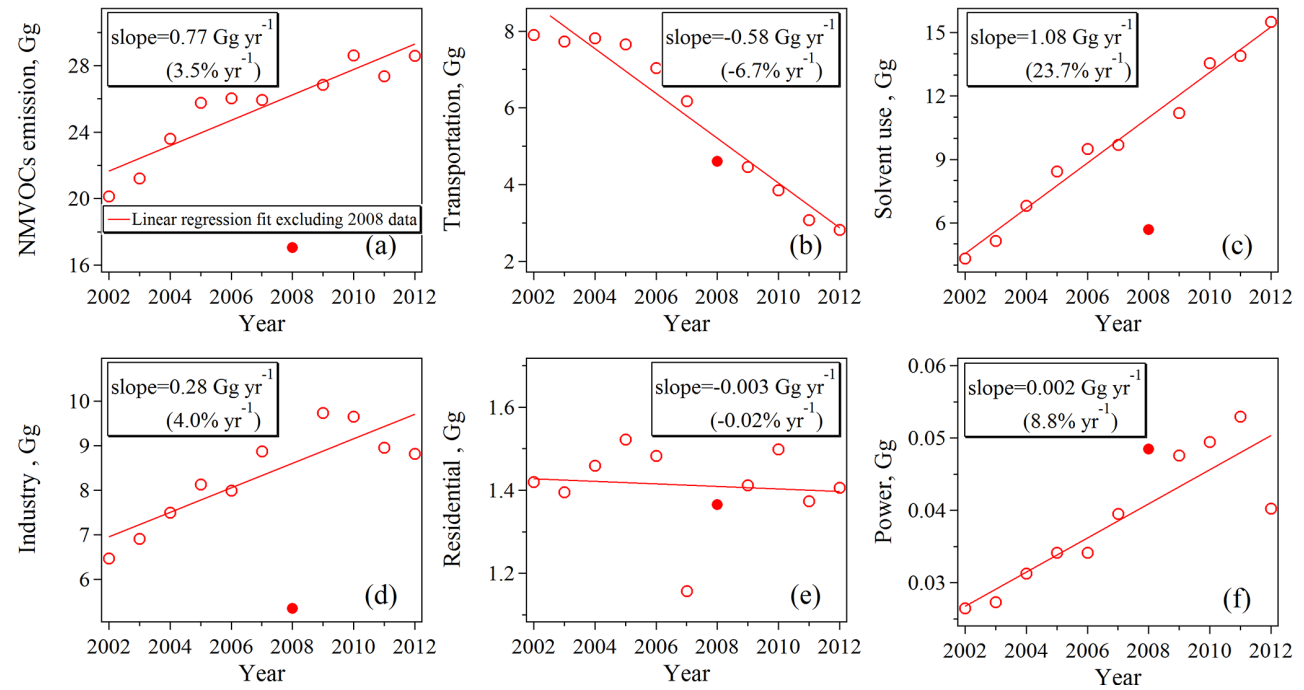

Figure 1. Anthropogenic NMVOC emissions in Beijing during August from 2002 to 2012 reported by the MEIC inventory (http://www. meicmodel.org): (a) total emissions, (b) transportation, (c) solvent use, (d) industry, (e) residential activities, and (f) power plants. Owing to the influence from the short-term control measures for the Beijing Olympic Games, the emission data for August 2008 (the red filled circle) were excluded from the linear regression fits (the red solid lines).

Table 1. Summertime NMHC measurements data sets at the PKU site in Beijing from 2002 to 2013.

\begin{tabular}{llll}
\hline Year & Instruments & Observation period (time resolution) & Reference \\
\hline 2002 & Online GC-FID (PKU) & 8-30 September $(30 \mathrm{~min}) ;$ & - \\
2004 & Canister-offline GC-MS/FID & 11-20 August & (Lu et al., 2007) \\
2005 & Online GC-MS/FID (ESRL) & 1-27 August $(30 \mathrm{~min})$ & (Liu et al., 2009a) \\
2006 & Online GC-FID (RCEC) & 15-24 August $(1 \mathrm{~h})$ & (Xie et al., 2008) \\
2007 & Online GC-FID/PID & 7-31 August $(30$ min) & (Zhang et al., 2014) \\
2008 & Online GC-MS/FID (RCEC) & 27 July-30 August $(1 \mathrm{~h})$ & (Wang et al., 2010a) \\
2009 & Online GC-FID/PID & 8-31 August $(30$ min $)$ & (Zhang et al., 2014) \\
2010 & Online GC-MS/FID (PKU) & 12-31 August $(1 \mathrm{~h})$ & (Yuan et al., 2012) \\
2011 & Online GC-MS/FID (PKU) & 3 August-13 September $(1 \mathrm{~h})$ & (Wang et al., 2014a) \\
2012 & Online GC-MS/FID (PKU) & 1-31 August $(1 \mathrm{~h})$ & - \\
2013 & Online GC-MS/FID (PKU) & 7-25 August $(1 \mathrm{~h})$ & - \\
\hline
\end{tabular}

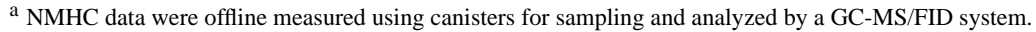

references are provided in Table 1. During August 2004, ambient air samples were collected in canisters and were analyzed offline for NMHCs using a GC-MS system in the lab to detect target compounds (Liu et al., 2005). For the other years, atmospheric NMHCs were measured by online instruments. During September 2002, an online GC-FID system developed by Peking University was used to measure mixing ratios of $\mathrm{C} 4-\mathrm{C} 12$ hydrocarbons, including $\mathrm{C} 4-\mathrm{C} 12$ alkanes, $\mathrm{C} 4-\mathrm{C} 6$ alkenes, and $\mathrm{C} 6-\mathrm{C} 8$ aromatics, with a time resolution of $30 \mathrm{~min}$. Ambient C4-C12 NMHCs were first initially trapped on carbon molecular sieves (i.e., the absorbent tube); then, they were vaporized by thermal desorption and transferred into a deactivated quartz capillary for secondary enrichment (i.e., the enrichment trap). Then, the enrichment trap was rapidly heated to $200^{\circ} \mathrm{C}$, and the target compounds were carried into the GC-MS/FID system for separation and detection. In August 2005, mixing ratios of NMHCs were measured using an online GC-MS/FID system developed by the Earth System Research Lab (ESRL; NOAA, US). A detailed description of this system was provided by Goldan et al. (2004). During August 2006 and 2008, ambient levels of NMHCs were measured using an online GC-FID system built by the Research Center for Environmental Changes (RCEC; Taiwan). A detailed description of this system and QA/QC procedures can be found in Wang et al. (2004). During August 2007 and 2009, ambient NMHCs were measured using a commercial GC-FID/PID system (Syntech Spectra GC955 series 600/800 analyzer) (Xie et al., 2008; Zhang et al., 2014). From 2010 to 2013, NMHCs were measured using a cryogen-free online GC-MSD/FID system developed 
by Peking University. A detailed description of this system and QA/QC procedures can be found in Yuan et al. (2012) and Wang et al. (2014b).

\subsection{Positive matrix factorization (PMF) model}

A PMF model, developed by the US Environmental Protection Agency (US EPA; V3.0, http://www.epa.gov/heasd/ research/pmf.html), was applied to NMHC measurement data during August from 2004 to 2012 for source apportionment. The PMF is a multivariate factor analytical tool that decomposes the speciated measurement data matrix $\mathbf{x}$ of $i$ by $j$ dimensions into two matrices - factor profiles (f) and factor contributions (g) (US EPA, 2008):

$x_{i j}=\sum_{k=1}^{p} g_{i k} f_{i k}+e_{i j}$,

where $p$ is the number of factors and $e_{i j}$ is the residual for each sample/species. The PMF solution minimizes the objective function $Q$ based on the uncertainties $u_{i j}$ :

$Q=\sum_{i=1}^{n} \sum_{j=1}^{m}\left[\frac{x_{i j}-\sum_{k=1}^{p} g_{i k} f_{k j}}{u_{i j}}\right]^{2}$

where $m$ and $n$ are the numbers of samples and chemical species, respectively.

In this study, the measurement data for $16 \mathrm{NMHC}$ species, including C2-C6 straight alkanes, C6-C8 aromatics, acetylene, and $\mathrm{C} 2-\mathrm{C} 4$ alkenes (Table S1), that were obtained at the PKU site in selected summer periods over 9 years from 2004 to 2012 were combined into one single data set of 6062 samples to derive a consistent set of source profiles. According to the physical plausibility of PMF-resolved factors, the

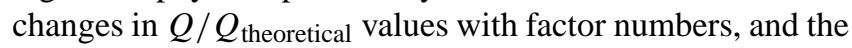
fit between predicted concentrations and measured values, we determined that the number of factors for the PMF solution in this study was four. To investigate the free rotation of the PMF factors, the PMF model was run 33 times with $F_{\text {PEAK }}$ ranging from -5 to 5 , and the results with no rotation $\left(F_{\text {PEAK }}=0\right)$ were selected.

\section{Results and discussion}

\subsection{Anthropogenic NMHC emissions during August in Beijing reported by the MEIC inventory}

The anthropogenic NMHC emissions during August in Beijing from 2002 to 2012 that estimated by the MEIC inventory are depicted in Fig. 1. It should be pointed out that the NMHC emissions for August 2008 were excluded from linear regression fits for NMHC emissions from 2002 to 2012, owing to the influence of short-term control measures for the Beijing Olympic Games during that time (Wang et al., 2010a;

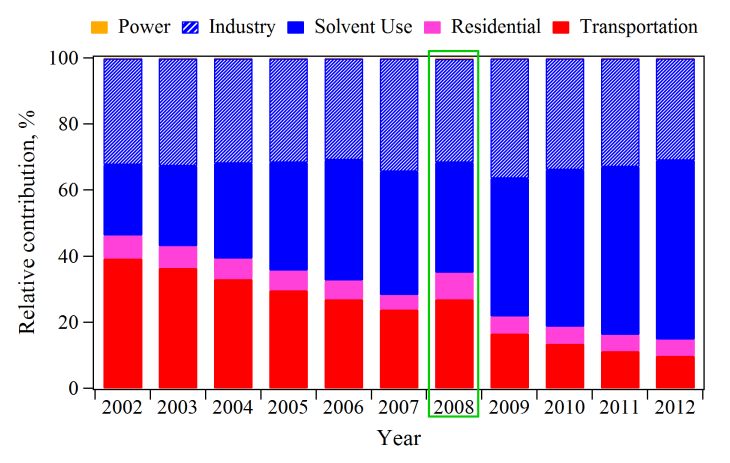

Figure 2. Relative contributions of transportation, residential activities, solvent use, industry, and power plants to anthropogenic NMVOC emissions in Beijing during August from 2002 to 2012 reported by the MEIC inventory (http://www.meicmodel.org).

Su et al., 2011). Total anthropogenic NMHC emissions during August in Beijing increased at a rate of $3.5 \% \mathrm{yr}^{-1}$ from 2002 to 2012 (Fig. 1a). Transportation-related NMHC emissions during August in Beijing decreased at a rate of $6.7 \%$ $\mathrm{yr}^{-1}$ (Fig. 1b), similar to previous inventory results for onroad vehicles (Wang et al., 2010b; Wu et al., 2011; Lang et al., 2012), whereas anthropogenic NMHC emissions from solvent use, industry, and power plants all showed significant increasing trends, with respective rates of $23.7 \% \mathrm{yr}^{-1}, 4.0 \%$ $\mathrm{yr}^{-1}$, and $8.8 \% \mathrm{yr}^{-1}$ (Fig. 1c-f).

Figure 2 shows the relative contributions of five source categories to total anthropogenic NMHC emissions during August in Beijing from 2002 to 2012. It should be pointed out that the source structure of NMHC emissions for August 2008 was different from those for August 2007 and 2009 because a series of short-term control measures for the Beijing Olympic Games were conducted during that time (Wang et al., 2010a; Su et al., 2011). For the other years, the relative contributions of solvent use to NMHC emissions during August increased gradually from $21 \%$ (2002) to $54 \%$ (2012), whereas the relative contributions of transportation-related emissions decreased from 39 to $10 \%$. Residential sources exhibited slight decreasing contributions to NMHC emissions from 7 to $5 \%$, while industry contributions did not show significant changes during August from 2002 to 2012, with values of $31-32 \%$.

\subsection{Temporal changes in ambient NMHC levels}

In contrast to the MEIC inventory, which reported an increasing trend in total anthropogenic NMHC emissions during August in Beijing, mixing ratios of NMHCs (i.e., the sum of ambient mixing ratios for $16 \mathrm{C} 2-\mathrm{C} 8 \mathrm{NMHC}$ species; Table S1) measured at the PKU site and ambient levels of VOCs (i.e., the sum of $55 \mathrm{C} 2-\mathrm{C} 8$ hydrocarbons and halocarbons) observed at Beijing Meteorological Tower (BMT), another urban site (Wang et al., 2012), during summer, both exhibited declining trends from the year 2003. This discrepancy 


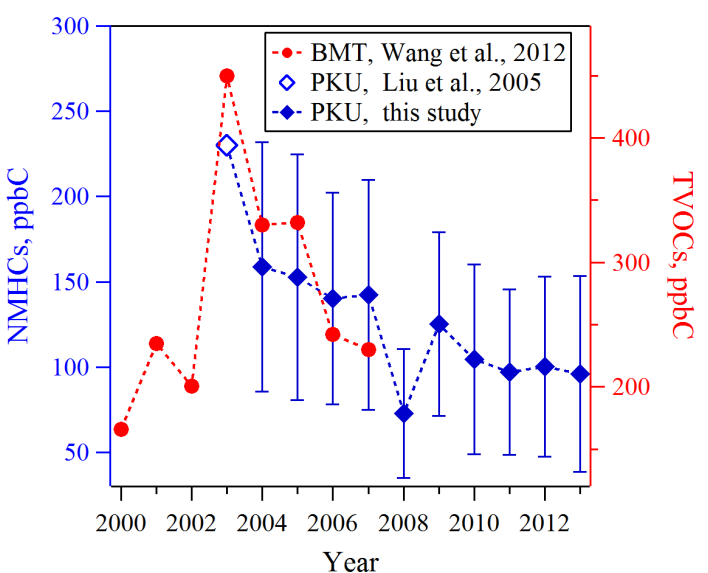

Figure 3. Temporal changes in NMHC mixing ratios (i.e., the sum of mixing ratios for 16 measured $\mathrm{C} 2-\mathrm{C} 8$ hydrocarbons) measured at the PKU site (blue diamonds) during August from 2003 to 2012 and summertime levels of TVOCs (i.e., the sum of 55 measured C4-C10 hydrocarbons and halocarbons) measured at the Beijing Meteorological Tower (BMT) site (red dots) reported by Wang et al. (2012) from 2000 to 2007. The error bars correspond to standard deviations of NMHC levels for each year.

of NMHC temporal changes between measurements and the MEIC inventory suggests the possible uncertainty of NMHC emission trends for one or more sources in the current inventory.

Vehicle exhaust, gasoline vaporization, paint and solvent utilization, natural gas (NG) and liquefied petroleum gasoline (LPG) leakage were considered to be important sources of NMHCs in Beijing during summer (Song et al., 2007; Shao et al., 2011; Wang et al., 2014a). To preliminarily investigate temporal changes in NMHC emissions from these sources, we used a simple linear regression fit to analyze the trends in mixing ratios of some individual NMHC species that were measured in this study. The Pearson correlation coefficient $(r)$ and $p$ value associated with the standard F-statistic test were used to determine the significance of these trends: trends were considered significant at the $0.05\left(p<0.05 ;{ }^{*}\right)$ or 0.01 level $\left(p<0.01 ;^{* *}\right)$. The slopes of these fits, which corresponded to the increasing (positive) or decreasing (negative) rates ( $\mathrm{ppbv} \mathrm{yr}^{-1}$ ) of a given NMHC species, were divided by the fitted mixing ratios for the first year to calculate relative rates of their temporal changes $\left(\% \mathrm{yr}^{-1}\right)$. It is important to note that the NMHC mixing ratios in August 2008 were markedly lower than those in other years (Figs. 4-7), owing to the influence of short-term NMHC control measures implemented for the Beijing Olympic Games during that time; therefore, the measurement data for August 2008 were excluded from the trend analysis.
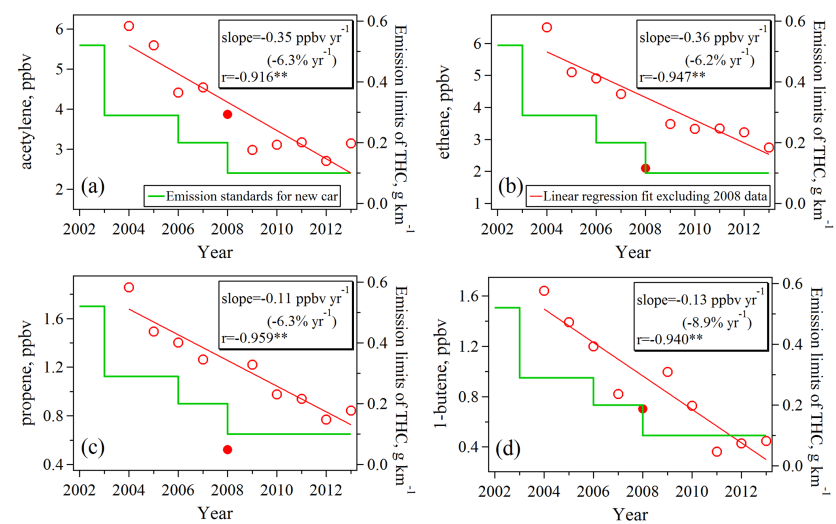

Figure 4. Temporal changes in ambient levels for (a) acetylene, (b) ethene, (c) propene, and (d) 1-butene measured at the PKU site during August from 2004 to 2013. The dark green staircase-pattern lines correspond to the emission limits of total hydrocarbons (THC) from light-duty vehicles. Owing to the influence from the short-term control measures for the Beijing Olympic Games, the measurement data for August 2008 (the red filled circle) were excluded from the linear fits. The trends that are significant at the 0.05 and $0.01 \mathrm{lev}$ els were marked by a single asterisk $\left(^{*}\right)$ and a double asterisk $\left(^{* *}\right)$, respectively.

\subsubsection{Vehicle exhaust: acetylene and alkenes}

Acetylene and alkenes emissions were mainly associated with combustion processes (Baker et al., 2008; Liu et al., 2008). The seasonal variations of NMHC sources in Beijing suggested that the evaporation of gasoline and solvent showed larger contributions during summer whereas coal combustion contributed more NMHC emissions during winter (Wang et al., 2014a). The relative contribution of coal burning to NMHC emissions during summer in Beijing can be neglected, and thus the main source of acetylene and alkenes emissions is vehicle exhaust (Song et al., 2007; Liu et al., 2009a; Wang et al., 2010a). Ambient mixing ratios of acetylene, ethene, propene, and 1-butene all exhibited significant declines during August from 2004 to 2013, with relative rates of decline between $6.2 \% \mathrm{yr}^{-1}$ and $8.9 \% \mathrm{yr}^{-1}$ (Fig. 4). This finding is in agreement with the decline in transportation-related NMHC emissions during August reported by the MEIC inventory (Fig. 1b).

The significant decline in transportation-related NMHC emissions in Beijing can be mostly attributed to the implementation of more stringent emission standards for new vehicles (Tables S2-S3 and the dark green staircase-pattern lines in Fig. 4). The regulation for new vehicle tail pipe emissions was first implemented in Beijing in 1990 with the preEuro I standard, followed by Euro I (1999), Euro II (2003), Euro III (2005), Euro IV (2008), and Euro V (2013). For the Euro IV and V standards, the limits for total hydrocarbon (THC) emissions from light-duty gasoline vehicles (LDGV) were reduced to $0.1 \mathrm{~g} \mathrm{~km}^{-1}$, which was approximately 1 or- 
der of magnitude lower than that of the Euro I standard (Table S3). This would result in the decline of THC emission factors from LDGV exhaust (Wu et al., 2011; Huo et al., 2012), which decreased from 0.7 (Euro I) to 0.02 (Euro IV) $\mathrm{kg} \mathrm{km}^{-1}$ (Fig. S1). Although the population of vehicles in Beijing tripled from 2002 to 2012, NMHC emissions from transportation-related sources decreased during this time due to the implementation of stricter emissions standards.

Besides tightening hydrocarbon emission standards for new vehicles, the Beijing government also implemented specific measures to control hydrocarbon emissions from in-use vehicles (Wu et al., 2011). (1) The inspection and maintenance (I/M) program for in-use vehicles was implemented by the Beijing Environmental Protection Bureau (EPB) from 1994. (2) The Beijing EPB also carried out some retrofit programs for light-duty vehicles and gasoline-powered taxis. (3) Some high-emitting vehicles were restricted to driving in specific regions of Beijing during specific time periods. The yellow-labeled vehicles (YLVs, vehicles that fail to meet the Euro I standard for tailpipe emissions) were banned to drive inside the Second-Ring Road of Beijing from 2003. The restriction area subsequently expanded to the SixthRing Road. Motorcycles were not allowed to drive within the Fourth-Ring Road since 2001. Heavy-duty trucks were banned to drive within the Fourth-Ring Road during daytime (06:00-23:00 LT). (4) Scrapping high-emitting YLVs is another method to reduce hydrocarbon emissions from inuse vehicles. (5) There are another control measures that were implemented in Beijing to reduce traffic-related hydrocarbon emissions, such as improving fuel quality, developing the public transport system, promoting vehicles powered by green energy (e.g., compressed natural gas and electricity), implementing temporal control measures that restricted drivers on 1 day a week by license plate number, and some economic policies (Wu et al., 2011). The recent study by Wu et al. (2011) evaluated the effectiveness of these control measures to reduce traffic-related hydrocarbon emission and found that the implementation of stringent emission standards for new vehicles contributed more than $90 \%$ of the reduction benefit for hydrocarbon emission from on-road vehicles.

\subsubsection{Gasoline vaporization: $i$-butane and $i$-pentane}

Besides vehicle exhaust, gasoline vaporization is another important source of C4-C5 alkanes, especially for $i$-butane and $i$-pentane (Harley et al., 1992; Liu et al., 2008). Different from the decline that was observed for acetylene and alkenes levels, the mixing ratios of $i$-butane and $i$-pentane measured at the PKU site during August increased from 2004 to 2007, and then decreased from 2007 to 2013 by 33 and $65 \%$, respectively (Fig. 5).

Gasoline vapor recovery systems were installed at 1265 gas stations, and in 1026 trucks and 38 tankers during September 2007-May 2008, as part of the control measures
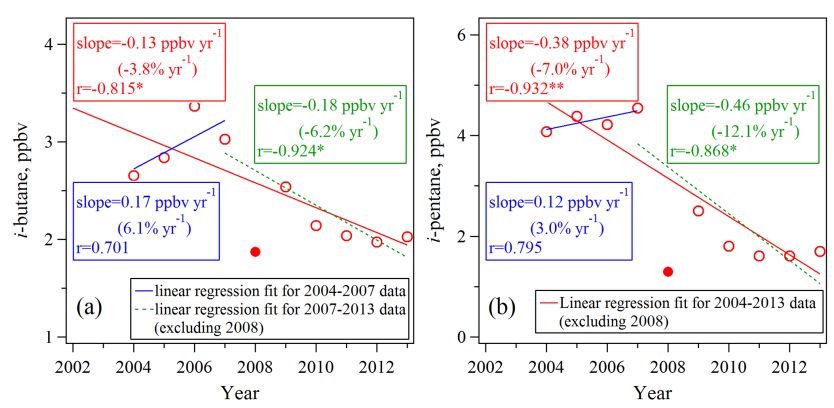

Figure 5. Temporal changes in ambient levels for (a) $i$-butane and (b) $i$-pentane measured at the PKU site during August from 2004 to 2013. The solid red lines represent linear regression fit for mixing ratios of $i$-butane and $i$-pentane during August from 2002 to 2013 excluding August 2008 data (the red filled circle). The dashed and solid blue lines represent linear regression fits for ambient measurements during August from 2004 to 2007 and during August from 2007 to 2013 (excluding August 2008 data), respectively.

implemented to reduce hydrocarbon emissions from gasoline vaporization and to improve air quality in Beijing. Steep declines in C4-C5 alkanes levels were observed between 2007 and 2009 (17\% for butanes, $36 \%$ for pentanes), which corresponded to the period of time in which gasoline vapor recovery systems were being installed in Beijing, suggesting the effectiveness of these systems for reducing hydrocarbon emissions from gasoline vaporization.

\subsubsection{Paint and solvent utilization: benzene, toluene, ethylbenzene, and xylenes}

Traffic-related emission and the use of paint and solvent were considered to the two most important sources of aromatic emissions in Beijing (Wang et al., 2012; Wei et al., 2008; Liu et al., 2009b; Wang et al., 2014a). As shown in Fig. 6, the mixing ratios of benzene, toluene, ethylbenzene, and xylenes (BTEX) measured at the PKU site during August/September also showed a decreasing trend from 2002 to 2013, similar with those for acetylene and alkenes. However, the relative rates of decline for BTEX levels $\left(2.8-5.6 \% \mathrm{yr}^{-1}\right)$ were lower than those for tracers of vehicle exhaust $(6.2-8.9 \%$ $\left.\mathrm{yr}^{-1}\right)$. This finding indicates that either the NMHC emissions from paint and solvent utilization did not decrease during this study period or their relative decline rates were lower than that for NMHC emissions from vehicle exhaust.

The two main uses for paint and solvent in Beijing are to paint buildings and automobiles ( $\mathrm{Su}$ et al., 2011). During 2002-2012, the production of architectural coatings (e.g., siding materials and house/building paint) in Beijing increased from 43000 to 110000 ton (Beijing Statistical Yearbook 2002-2012), while the production of automobiles increased from 150000 to 1670000 vehicles (Chinese Automobile Industry Yearbook 2002-2012). Meanwhile, more stringent emission standards for paint and solvent utilization 


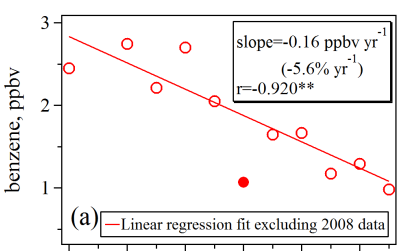

$\begin{array}{llllll}2002 & 2004 \quad 2006 \quad 2008 \quad 2010 \quad 2012\end{array}$ Year
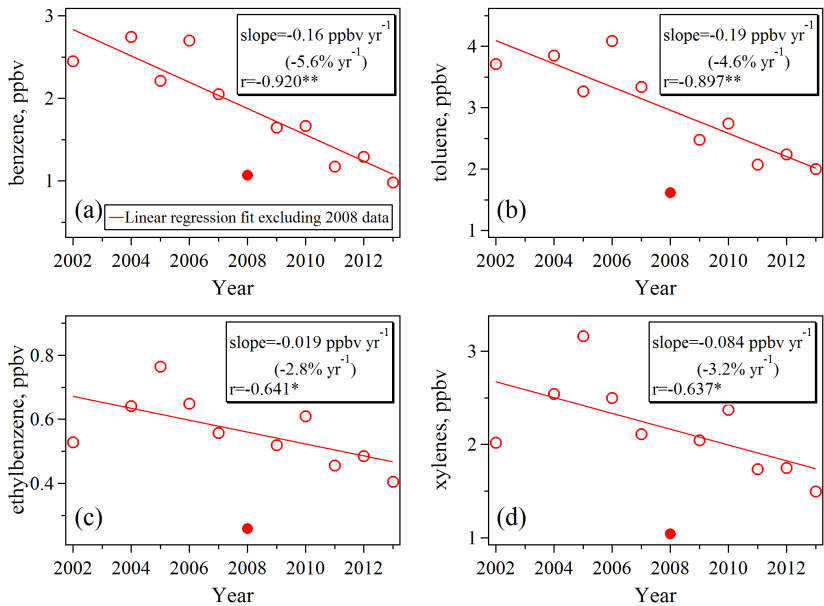
Year

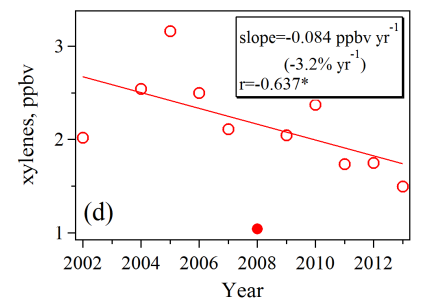

Figure 6. Temporal changes in ambient levels for (a) benzene, (b) toluene, (c) ethylbenzene, and (d) xylenes measured at the PKU site during August from 2002 to 2013. The solid red lines represent linear regression fits for aromatics levels during August from 2012 to 2013 excluding data for August 2008 (the red filled circle).

have been implemented and updated in recent years. Table S4 summarizes the limits on benzene and other aromatics, as well as the implementation dates of national standards on paint for automobiles, woodenware, exterior/interior walls, floors, and toys. In addition, a series of regulations regarding the use of solvent-based coatings with high aromatic emissions was also implemented during the past decade in Beijing. The use of solvent-based coatings as water-proof material for architectural decoration was restricted from 2003 in Beijing and then was banned from July 2005 by the Beijing Municipal Construction Committee. For the automobile industry, the cleaner production standard-automobile manufacturing (painting) was implemented in December 2006 (HJ/T 293-2006) that banned the use of paint and solvents containing benzene, and encouraged the use of water-based and powder coatings. The stringent limits on aromatic content in paint and solvents and the increasing use of waterbased coatings should reduce the emission factors of BTEX for paint and solvent use. Due to the difficulty in obtaining accurate usage data and the lack of studies documenting temporal changes in NMHC emission factors for paint and solvent use, it is still a challenge to investigate NMHC emission trends for paint and solvent use.

\subsubsection{NG and LPG usage: ethane and propane}

The use of NG and LPG was believed to be an important source of C2-C4 alkanes (Blake and Rowland, 1995; Katzenstein et al., 2003). In contrast to the declines in ambient levels for acetylene, alkenes, C4-C5 alkanes, and BTEX, mixing ratios of ethane measured at the PKU site during August exhibited a significant increase of $\sim 50 \%(\sim 1.6 \mathrm{ppbv})$ between 2004 and 2013 (Fig. 7a). This rapid increase in ethane levels
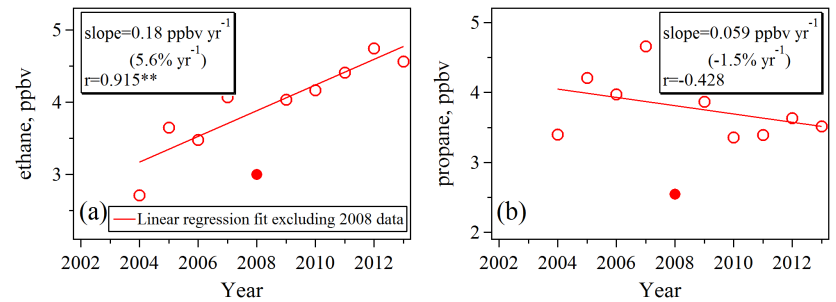

Figure 7. Temporal changes in ambient levels for (a) ethane and (b) propane measured at the PKU site during August from 2004 to 2013. The solid red lines represent linear regression fits for ethane and propane mixing ratios excluding data for August 2008 (the red filled circle).

measured at the PKU site can not be explained by the $50 \mathrm{pptv}$ rise in background ethane reported by Simpson et al. (2012), and therefore it is possibly associated with the increase in ethane emissions in Beijing. Mixing ratios of propane measured at the PKU site during August did not show a significant trend during 2004-2013, with ambient levels that fluctuated between 3.4 and 4.7 ppbv (Fig. $7 b$ ).

NG and LPG are considered to be cleaner sources of energy than coal and gasoline, and therefore their supply and consumption have rapidly increased in Beijing during recent years. The consumption of NG in Beijing increased from 2.5 to 8.4 billion $\mathrm{m}^{3}$ during $2004-2012\left(29 \% \mathrm{yr}^{-1}\right)$, while the supply of LPG increased from 0.16 to 0.45 million ton $\left(23 \% \mathrm{yr}^{-1}\right.$ ) during the same period of time (Beijing Statistical Yearbook 2004-2012). Besides the use of NG and LPG, transportation-related emission was also considered to be an important source of propane and ethane in Beijing. In the emission inventory built by $\mathrm{Li}$ et al. (2014), transportation was the second largest contributor to ethane and propane in Beijing, only after industrial emission. In addition, the PMF source apportionment study by Song et al. (2007) also suggested that vehicular exhausts were an important source of ethane and propane in Beijing, with relative contributions of 43 and $46 \%$, respectively. Therefore, the temporal changes in ethane and propane levels measured at the PKU site might be the combined result of decreasing transportation emissions and increasing NG and LPG emissions in Beijing.

\subsection{Temporal changes in NMHC sources obtained by the PMF model}

Based on the preliminary analyses of NMHC measurements in Sect. 3.2, we found that the temporal changes in mixing ratios of NMHC species from vehicle exhaust measured at the PKU site were consistent with the trend in transportationrelated NMHC emissions during August in Beijing reported by the MEIC inventory. However, the trend analysis of BTEX levels can not provide a definitive evaluation of temporal changes in NMHC emissions from paint and solvent utilization. To further investigate NMHC emission trends for major 

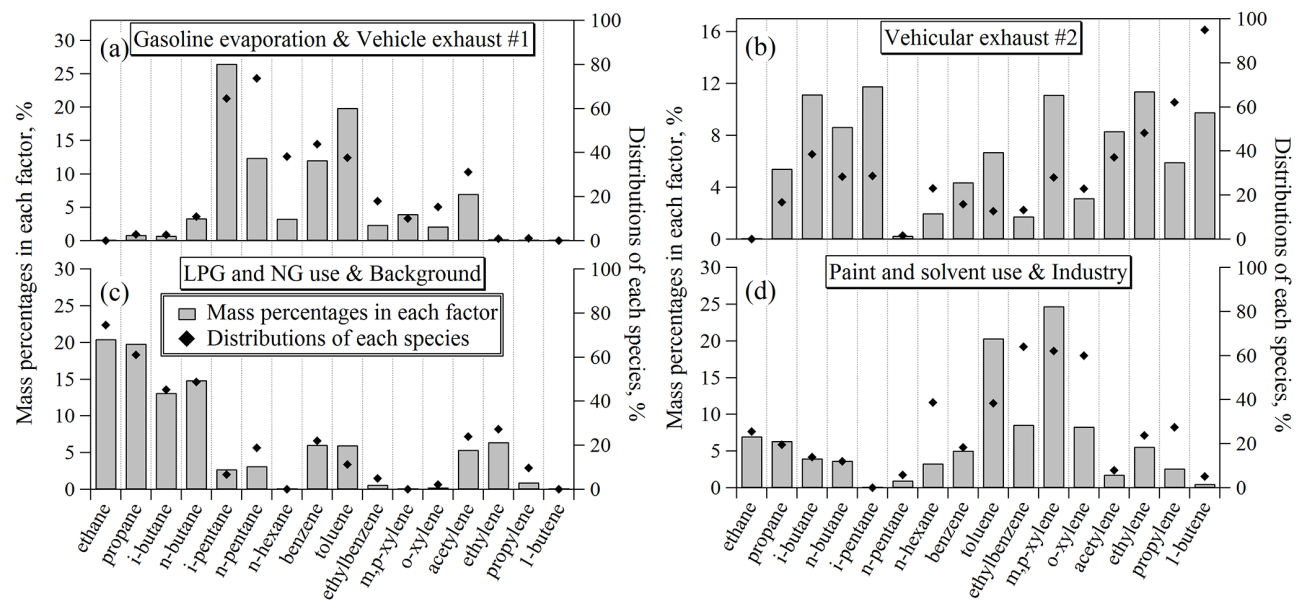

Figure 8. Profiles of four PMF-resolved factors (gray bars) and distributions of each species among these factors (black diamonds): (a) gasoline evaporation and vehicle exhaust no. 1, (b) vehicle exhaust no. 2, (c) LPG and NG use and background, and (d) paint and solvent use and industry.
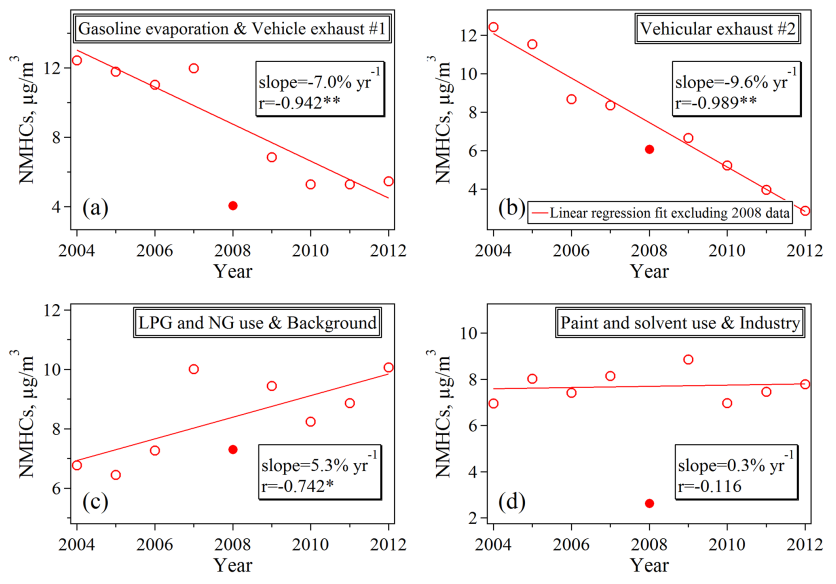

Figure 9. Temporal changes in NMHC concentrations during August from 2004 to 2012 contributed by four PMF-resolved factors: (a) gasoline and vehicle exhaust no. 1, (b) vehicle exhaust no. 2, (c) NG and LPG use and background, and (d) paint and solvent use and industry. The red solid lines represent linear regression fits of NMHC concentrations from each source during August from 2004 to 2012, excluding data for August 2008 (the red filled circle).

sources, a PMF model was applied to these NMHC measurements during August from 2004 to 2012 for source apportionment and to calculate NMHC concentrations from different sources in each year.

\subsubsection{Identification of PMF factors}

The profiles for the four PMF-resolved factors (i.e., the mass percentage of individual species in each factor) and the distributions of each species among these factors (i.e., the relative contributions of PMF factors to each NMHC species) are shown in Fig. 8.
As shown in Fig. 8a, the first factor was characterized by high levels of pentanes, which were considered to be important components of gasoline vaporization (Harley et al., 1992; Zhang et al., 2013). This factor also consisted of acetylene, benzene, and toluene, which can be emitted from vehicle exhaust (Liu et al., 2008). The second factor had the largest contributions to acetylene and C2-C4 alkenes (Fig. 8b), which are typically associated with vehicle exhaust (Parrish, 2006; Baker et al., 2008). These two transportationrelated factors were referred to as gasoline evaporation and vehicular exhaust no. 1 and vehicular exhaust no. 2, respectively.

The third factor was characterized by high levels of light alkanes (Fig. 8c). Ethane and propane are commonly associated with the leakage of NG and LPG, respectively (Blake and Rowland, 1995; Katzenstein et al., 2003). It is important to point out that this factor might be influenced by background air due to the long atmospheric lifetimes of these alkanes (Atkinson et al., 2006). Therefore, this factor was referred to as NG and LPG use and background.

The fourth factor largely consisted of toluene, ethylbenzene, and xylenes (Fig. 8d). These aromatic compounds can be emitted from both paint and solvent utilization (Yuan et al., 2010) and chemical industries (Liu et al., 2008). This factor is also the largest contributor (39\%) to $n$-hexane, which is one product of crude oil refining and is commonly used as solvent in industrial processes. In addition, this factor is the second largest contributor $(28 \%)$ to ethene and propene, which can also be emitted from petrochemical industry (Jobson et al., 2004; Wei et al., 2014) besides vehicular exhaust. Based on these thoughts, the fourth factor was considered to be not only related to paint and solvent use but also influenced by industrial sources, and therefore it was referred to as paint and solvent use and industry. 


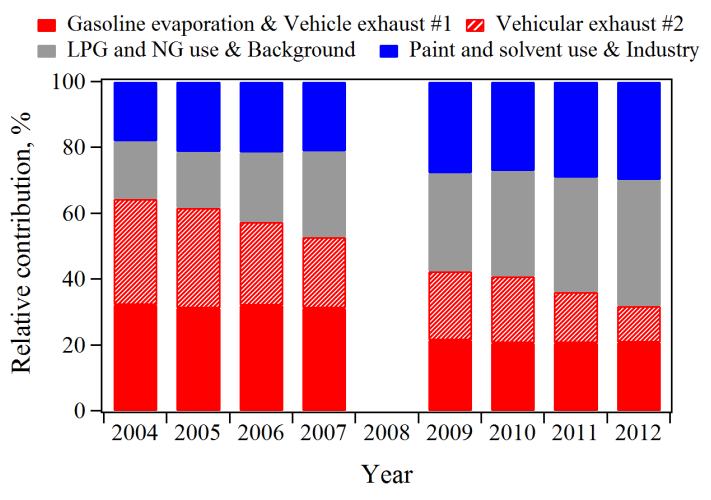

Figure 10. Relative contributions of four PMF-resolved factors to ambient concentrations of NMHCs $\left(\mu \mathrm{g} \mathrm{m}^{-3}\right)$ measured at the PKU site during August from 2004 to 2012. Owing to the influence of the short-term control measures for the Beijing Olympic Games during August 2008, relative contributions of these four PMF-resolved factors were not shown in this figure.

\subsubsection{Temporal trends in NMHC concentrations from different sources}

The temporal changes in NMHC concentrations (i.e., the sum of concentrations for 16 measured NMHC species) contributed by each PMF-resolved factor during August from 2004 to 2012 are shown in Fig. 9a-d. The NMHC concentrations from gasoline evaporation and vehicle exhaust no. 1 and vehicle exhaust no. 2 decreased significantly by $56 \%$ and $77 \%$, respectively (Fig. 9a and b). The sum of NMHC concentrations from these two transportation-related sources decreased by $66 \%$ between August 2004 and August 2012, which is close to the relative decline of $64 \%$ for transportation-related emissions during August in Beijing reported by the MEIC inventory (Fig. 1b). The NMHC concentrations contributed by $N G$ and $L P G$ use and background exhibited a significant increase of $5.3 \% \mathrm{yr}^{-1}$ during August from 2004 to 2012 (Fig. 9c).

The PMF results indicate that there were no significant temporal changes in the contributions of paint and solvent use and industry to NMHC concentrations during August from 2004 to 2012 (Fig. 9d). This result is in strong contrast to the rapid increase in NMHC emissions from solvent use and industry $\left(8.8 \% \mathrm{yr}^{-1}\right)$ that was reported by the MEIC inventory. Paint and solvent are used in a wide variety of residential and industrial processes and it is difficult to obtain accurate usage data and representative NMHC emission factors for all of these processes. The NMHC emissions from paint and solvent use are usually calculated based on either solvent consumption/production data (solvent mass balance approach) or per capita/employment emission factors (Klimont et al., 2002; Su et al., 2011). Due to the lack of NMHC emission factor measurements and the absence of detailed information on paint and solvent use in China, some surrogate indicators (e.g., population, GDP) were often used to project
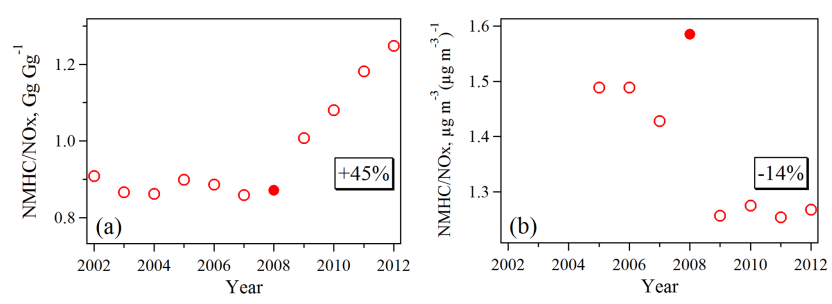

Figure 11. Temporal changes in (a) emission ratios of NMHCs to $\mathrm{NO}_{\mathrm{x}}\left(\mathrm{Mg} \mathrm{Mg}^{-1}\right)$ from 2002 to 2012 in Beijing reported by the MEIC inventory and (b) concentration ratios of NMHCs to $\mathrm{NO}_{\mathrm{x}}$ $\left(\mu \mathrm{g} \mathrm{m}^{-3}\left(\mu \mathrm{g} \mathrm{m}^{-3}\right)^{-1}\right)$ obtained by ambient measurements during August at the PKU site from 2005 to 2012.

future NMHC emissions from this source (Bo et al., 2008). This would result in some uncertainties in predicted NMHC emissions from paint and solvent use.

The PMF results also suggest that there have been some changes in NMHC sources in Beijing during August from 2004 to 2012. As shown in Fig. 10, the relative contributions of transportation-related sources to NMHC concentrations (i.e., the sum of gasoline evaporation and vehicle exhaust no. 1 and vehicle exhaust no. 2) decreased from 64 to $32 \%$, while the relative contributions of paint and solvent use and industry to NMHC concentrations increased from 18 to $30 \%$. The relative contributions for $N G$ and $L P G$ use and background increased from 18 to $38 \%$.

\subsection{Temporal trends in $\mathrm{NMHC}$ to $\mathrm{NO}_{\mathrm{x}}$ ratios}

Anthropogenic $\mathrm{NO}_{\mathrm{x}}$ are mainly emitted from combustion processes, such as vehicle exhaust and coal combustion (Zhao et al., 2013), whereas NMHC species can also be emitted from non-combustion sources (e.g., paint and solvent use and fugitive emissions from the petrochemical industry). Comparing the emission ratio of $\mathrm{NMHC}$ to $\mathrm{NO}_{\mathrm{x}}$ between ambient measurements and emission inventories is another way to assess the accuracy of NMHC emissions and estimate the relative contribution of non-combustion sources to total NMHC emissions (Funk et al., 2001; Arriaga-Colina et al., 2004).

As shown in Fig. 11a, emission ratios of $\mathrm{NMHC}$ to $\mathrm{NO}_{\mathrm{x}}$ in Beijing reported by the MEIC inventory increased by $45 \%$ from 2005 to 2012, which was mainly attributed to the decreasing $\mathrm{NMHC} / \mathrm{NO}_{\mathrm{x}}$ ratios for transportation $(\sim 45 \%)$ and the increasing NMHC emissions from solvent use $(\sim 300 \%)$. However, the ambient measurements at the PKU site suggested that $\mathrm{NMHC} / \mathrm{NO}_{\mathrm{x}}$ concentration ratios decreased by $14 \%$ during August from 2005 to 2012 (Fig. 11b). One possible explanation for this discrepancy is that the rate of increase in NMHC emissions from solvent use was overestimated by the MEIC inventory. If we assumed that the NMHC emissions from paint and solvent use and industry did not exhibit significant changes during 2005-2012 according to the PMF results, the inferred emission ratios of $\mathrm{NMHC}$ to $\mathrm{NO}_{\mathrm{x}}$ would 
decrease by $\sim 11 \%$ from 2005 to 2012 , similar to the decline rate of $14 \%$ for $\mathrm{NMHC} / \mathrm{NO}_{\mathrm{x}}$ ratios measured at the PKU site.

It is important to note that there are some limitations and uncertainties associated with our evaluation of NMHC emission trends during August in Beijing using ambient measurements at the PKU site.

1. The NMHC measurement data in this study were obtained by seven different instruments (Table 1). To ensure the accuracy of NMHC data, intercomparisons among some of these systems were conducted in 2005, 2008, and 2010. The good agreements between the offline GC-MS/FID system coupled with canister sampling and the online GC-MS/FID systems developed by ESRL and RCEC were reported by Liu et al. (2009a) and Wang et al. (2010a), respectively. Additionally, the good agreements among canister-offline GC-MS/FID, online GC-FID/PID, and online GC-MS/FID developed by PKU were reported by Wang et al. (2014b) (Fig. S2).

2. The temporal change in meteorological conditions might be an influence factor for the temporal trends in NMHC mixing ratios. However, Zhang et al. (2014) found that the meteorological parameters (i.e., ambient temperature, wind direction speed, and precipitation) measured at the PKU site showed no significant changes during August from 2005 to 2011, and therefore the temporal changes in NMHC levels could reflect the trends of NMHC emissions during that time.

3. In this study, the NMHC emission trends during August in Beijing reported by the MEIC inventory were evaluated based on NMHC measurements at the PKU. In fact, NMHC sources in Beijing exhibited significant seasonal variations (Wang et al., 2014a), and thus temporal trends in NMHC emissions might be inconsistent during different seasons. Figure S3 compares mixing ratios of ethane, acetylene, 1,3-butadiene, benzene, and toluene measured during winter in Beijing (Barletta et al., 2005; Liu et al., 2005; Wang et al., 2014a). It can be found that the average levels for ethane, acetylene, benzene, and toluene during December 2011-January 2012 (Wang et al., 2014a) were lower than those for January-February 2011 and December 2002 (Barletta et al., 2005; Liu et al., 2005). However, these wintertime measurement data are not enough to investigate temporal trends in NMHC levels during winter in Beijing. More NMHC observations for other seasons except summer are needed in the future to investigate possible seasonal differences of NMHC trends.

4. In this study, the trend analyses for NMHC levels and sources were based on measurement data obtained at one urban site, whereas the temporal changes in NMHC emissions during August in Beijing reported by the
MEIC inventory were for the entire city. The regional measurements during 2009-2011 at 27 sites in Beijing suggested that NMHC levels in downtown and southern areas of Beijing were significantly higher than those for suburban/rural sites in northern and western regions (Fig. S5). The emission ratios of individual NMHC species relative to carbon monoxide showed good agreements between the PKU site and the 27 regional sites in Beijing (Fig. S6) (Wang et al., 2014a). In fact, the spatial distribution of industry and urbanization level in Beijing has been evolving during the last two decades (Wang et al., 2014a). Most industries had been moved out of downtown area and assembled in industrial parks in southern regions of Beijing (Wang et al., 2014a). Accompanied by the rapid economic development, southern suburban areas of Beijing have become more urbanized during these years. Although we can not obtain NMHC measurement data during the last decade for southern regions of Beijing, the Beijing government have selected five routine monitoring sites, two of them are located in southern regions, to measure the levels and speciation of NMHCs in entire Beijing since 2012. This will provide an opportunity for us to investigate the temporal trends of NMHCs at more sites of Beijing in the near future.

5. The daytime average mixing ratios of $\mathrm{O}_{3}$ measured at the PKU site increased by $30 \%$ between August 2005 and August 2011 (Zhang et al., 2014). Since the photodissociation of $\mathrm{O}_{3}$ is a primary pathway to form hydroxyl (OH) radicals (Lu et al., 2013), the rising $\mathrm{O}_{3}$ levels could result in the increase in $\mathrm{OH}$ abundance. Although there are no direct measurements of $\mathrm{OH}$ radical over long time periods in Beijing and its surrounding regions, the average abundance of $\mathrm{OH}$ radical $([\mathrm{OH}])$ can be estimated based on measured ratios of two hydrocarbons that have similar sources but different reaction rates with $\mathrm{OH}$ radical (McKeen et al., 1990; Ehhalt et al., 1998). In this study, the relative increase in daily average $\mathrm{OH}$ abundance at the PKU site was estimated to be $32.3 \%$ between August 2005 and August 2011 based on measured ratios of propene/ethene. The calculation details can be found in Sect. 5 of the supplement. The rate constants for $\mathrm{OH}$ oxidation of ethene $\left(k_{\mathrm{OH}}=9.0 \times 10^{-12} \mathrm{~cm}^{3}\right.$ molecule $\left.{ }^{-1} \mathrm{~s}^{-1}\right)$ and propene $\left(k_{\mathrm{OH}}=3.0 \times 10^{-11} \mathrm{~cm}^{3}\right.$ molecule $\left.\mathrm{e}^{-1} \mathrm{~s}^{-1}\right)$ were significantly higher than that for acetylene $\left(k_{\mathrm{OH}}=\right.$ $1.0 \times 10^{-12} \mathrm{~cm}^{3}$ molecule $\mathrm{e}^{-1} \mathrm{~s}^{-1}$ ), but the relative declines for these alkenes levels measured at the PKU site were close to that for acetylene (Fig. 4a-c). This indicates that the rise of atmospheric oxidizing capacity is not an important cause of the decline of hydrocarbon levels measured at the PKU site.

6. The temporal changes in NMHC source profiles were not considered in the PMF source apportionment in this 
study. However, the NMHC source profile for some sources possibly changed during the last decade, especially for aromatics, due to the controls on benzene fractions in paint and gasoline (Yuan et al., 2010). Additionally, Yuan et al. (2012) found that the PMF interpretations could be affected by photochemistry. Identifying this effect would require detailed analysis of photochemical removal of NMHC species, which is beyond the scope of this work.

\section{Conclusions}

The ambient mixing ratios of 16 NMHC species were measured during selected summer periods at an urban site in Beijing from 2002 to 2013. The temporal changes in NMHC levels were analyzed to evaluate temporal trends in anthropogenic NMHC emissions during August in Beijing reported by the most recent emission inventory for China (MEIC).

The MEIC inventory indicated that total anthropogenic NMHC emissions during August in Beijing significantly increased by $35 \%$ from 2002 to 2012 . The NMHC emissions from solvent use and industry during August increased by 237 and $40 \%$, respectively, whereas transportation-related NMHC emissions decreased by $67 \%$ during this time. In contrast to the increase in total NMHC emissions during August reported by the MEIC inventory, ambient levels of NMHCs measured at the PKU site exhibited a decline from 2003 to 2013. Mixing ratios of those NMHC species mainly from vehicle exhaust (e.g., C2-C4 alkenes and acetylene) decreased at rates of $6.2-8.9 \% \mathrm{yr}^{-1}$, which were comparable to the temporal changes in transportation-related emissions $\left(6.7 \% \mathrm{yr}^{-1}\right)$ reported by the MEIC inventory. The ambient levels for $i$-butane and $i$-pentane, which are mainly influenced by gasoline vaporization and vehicular exhaust, started to decrease from 2007, which corresponds to the time in which gasoline vapor recovery systems were being installed in Beijing. The decline rates of $2.8-5.6 \% \mathrm{yr}^{-1}$ for ambient aromatic levels were lower than those for vehicle exhaust tracers (i.e., acetylene and alkenes). Ethane levels exhibited a significant increase of $5.6 \% \mathrm{yr}^{-1}$ between 2004 and 2013; however, there were no significant changes in propane levels, with mixing ratios fluctuating between 3.4 and 4.7 ppbv.

To further evaluate NMHC trends for major sources, a PMF model was applied to ambient NMHC measurements for source apportionment and to calculate NMHC concentrations from different sources in each year. Four PMFresolved factors were identified: gasoline evaporation and vehicle exhaust no. 1, vehicle exhaust no. $2, N G$ and $L P G$ use and background, and paint and solvent use and industry. The sum of NMHC concentrations from two transportationrelated sources decreased by $66 \%$ from 2004 to 2012, which is comparable to the relative decline of $67 \%$ for transportation emissions reported by the MEIC inventory. However, the PMF results suggested that there were no significant tempo- ral changes in NMHC concentrations from solvent and paint use and industry during 2004-2012. This finding is in strong contrast to the rapid increase in NMHC emissions from solvent use and industry $\left(8.8 \% \mathrm{yr}^{-1}\right)$ during August reported by the MEIC inventory, indicating that the largest uncertainty in NMHC trends is possibly associated with emissions from paint and solvent use and industry. The PMF results also suggested that the relative contributions of NG and LPG use to NMHC emissions have become more important during the last decade; however, this source has not been included in the current inventory.

The comparison of temporal changes in $\mathrm{NMHC} / \mathrm{NO}_{\mathrm{x}}$ ratios between the MEIC inventory and ambient measurements were used to reanalyze NMHC emission trends from non-combustion sources (i.e., paint and solvent use and industry). The MEIC inventory indicated that emission ratios of $\mathrm{NMHC} / \mathrm{NO}_{\mathrm{x}}$ have increased in Beijing by $45 \%$ from 2005 to 2012. However, $\mathrm{NMHC} / \mathrm{NO}_{\mathrm{x}}$ ratios measured at the PKU site during August decreased by $\sim 15 \%$ during 2005 2012. The emission ratios of $\mathrm{NMHC} / \mathrm{NO}_{\mathrm{x}}$ that were inferred based on the PMF results exhibited a decline of $11 \%$ during 2005-2012, which was comparable to that for measured ratios of $\mathrm{NMHC} / \mathrm{NO}_{\mathrm{x}}$. This finding indicates that the rate of increase for NMHC emissions from paint and solvent use and industry might be overestimated in the MEIC inventory, and therefore, more studies are needed to verify NMHC emissions from paint and solvent and industry.

\section{The Supplement related to this article is available online at doi:10.5194/acp-15-1489-2015-supplement.}

Acknowledgements. This study was funded by the Natural Science Foundation for Outstanding Young Scholars (grant no. 41125018) and a Natural Science Foundation key project (grant no. 41330635). The research was also supported by the Collaborative Innovation Center for Regional Environmental Quality. Special thanks to William C. Kuster and Paul Goldan for the help in VOC measurements during 2005.

Edited by: G. Carmichael 


\section{References}

Arriaga-Colina, J. L., West, J. J., Sosa, G., Escalona, S. S., Ordunez, R. M., and Cervantes, A. D. M.: Measurements of VOCs in Mexico City (1992-2001) and evaluation of VOCs and CO in the emissions inventory, Atmos. Environ., 38, 2523-2533, doi:10.1016/j.atmosenv.2004.01.033, 2004.

Atkinson, R., Baulch, D. L., Cox, R. A., Crowley, J. N., Hampson, R. F., Hynes, R. G., Jenkin, M. E., Rossi, M. J., Troe, J., and IUPAC Subcommittee: Evaluated kinetic and photochemical data for atmospheric chemistry: Volume II - gas phase reactions of organic species, Atmos. Chem. Phys., 6, 3625-4055, doi:10.5194/acp-6-3625-2006, 2006.

Baker, A. K., Beyersdorf, A. J., Doezema, L. A., Katzenstein, A., Meinardi, S., Simpson, I. J., Blake, D. R., and Rowland, F. S.: Measurements of non-methane hydrocarbons in 28 United States cities, Atmos. Environ., 42, 170-182, doi:10.1016/j.atmosenv.2007.09.007, 2008.

Barletta, B., Meinardi, S., Rowland, F. S., Chan, C. Y., Wang, X. M., Zou, S. C., Chan, L. Y., and Blake, D. R.: Volatile organic compounds in 43 Chinese cities, Atmos. Environ., 39, 5979-5990, doi:10.1016/j.atmosenv.2005.06.029, 2005.

Blake, D. R. and Rowland, F. S.: Urban leakage of liquefied petroleum gas and its impact on Mexico City air quality, Science, 269, 953-956, doi:10.1126/science.269.5226.953, 1995.

Bo, Y., Cai, H., and Xie, S. D.: Spatial and temporal variation of historical anthropogenic NMVOCs emission inventories in China, Atmos. Chem. Phys., 8, 7297-7316, doi:10.5194/acp-8-72972008, 2008.

Ehhalt, D. H., Rohrer, F., Wahner, A., Prather, M. J., and Blake, D. R.: On the use of hydrocarbons for the determination of tropospheric OH concentrations, J. Geophys. Res., 103, 18981-18997, doi:10.1029/98jd01106, 1998.

EPA, U.S.: EPA Positive Matrix Factorization (PMF) 3.0 Fundamentals \& User Guide, 2008.

Funk, T. H., Chinkin, L. R., Roberts, P. T., Saeger, M., Mulligan, S., Figueroa, V. H. P., and Yarbrough, J.: Compilation and evaluation of a Paso del Norte emission inventory, Sci. Total Environ., 276, 135-151, doi:10.1016/s0048-9697(01)00776-8, 2001.

Goldan, P. D., Kuster, W. C., Williams, E., Murphy, P. C., Fehsenfeld, F. C., and Meagher, J.: Non-methane hydrocarbon and oxy hydrocarbon measurements during the 2002 New England Air Quality Study, J. Geophys. Res.-Atmos., 109, D21309, doi:10.1029/2003jd004455, 2004.

Harley, R. A., Hannigan, M. P., and Cass, G. R.: Respeciation of organic gas emissions and the detection of excess unburned gasoline in the atmosphere, Environ. Sci. Technol., 26, 2395-2408, doi:10.1021/es00036a010, 1992.

He, K. B.: Multi-resolution Emission Inventory for China (MEIC): model framework and 1990-2010 anthropogenic emissions, International Global Atmospheric Chemistry Conference, 17-21 September, Beijing, China, 2012.

Huo, H., Yao, Z. L., Zhang, Y. Z., Shen, X. B., Zhang, Q., Ding, Y., and He, K. B.: On-board measurements of emissions from lightduty gasoline vehicles in three mega-cities of China, Atmos. Environ., 49, 371-377, doi:10.1016/j.atmosenv.2011.11.005, 2012.

Jobson, B. T., Berkowitz, C. M., Kuster, W. C., Goldan, P. D., Williams, E. J., Fesenfeld, F. C., Apel, E. C., Karl, T., Lonneman, W. A., and Riemer, D.: Hydrocarbon source signatures in Hous- ton, Texas: Influence of the petrochemical industry, J. Geophys. Res.-Atmos., 109, D24305, doi:10.1029/2004jd004887, 2004.

Katzenstein, A. S., Doezema, L. A., Simpson, I. J., Blake, D. R., and Rowland, F. S.: Extensive regional atmospheric hydrocarbon pollution in the southwestern United States, Proc. Natl. Acad. Sci. USA, 100, 11975-11979, doi:10.1073/pnas.1635258100, 2003.

Klimont, Z., Streets, D. G., Gupta, S., Cofala, J., Lixin, F., and Ichikawa, Y.: Anthropogenic emissions of non-methane volatile organic compounds in China, Atmos. Environ., 36, 1309-1322, doi:10.1016/s1352-2310(01)00529-5, 2002.

Lang, J. L., Cheng, S. Y., Wei, W., Zhou, Y., Wei, X., and Chen, D. S.: A study on the trends of vehicular emissions in the BeijingTianjin-Hebei (BTH) region, China, Atmos. Environ., 62, 605614, doi:10.1016/j.atmosenv.2012.09.006, 2012.

Lefohn, A. S., Shadwick, D., and Oltmans, S. J.: Characterizing changes in surface ozone levels in metropolitan and rural areas in the United States for 1980-2008 and 1994-2008, Atmos. Environ., 44, 5199-5210, doi:10.1016/j.atmosenv.2010.08.049, 2010.

Lei, Y., Zhang, Q., He, K. B., and Streets, D. G.: Primary anthropogenic aerosol emission trends for China, 1990-2005, Atmos. Chem. Phys., 11, 931-954, doi:10.5194/acp-11-931-2011, 2011a.

Lei, Y., Zhang, Q., Nielsen, C., and He, K.: An inventory of primary air pollutants and $\mathrm{CO}_{2}$ emissions from cement production in China, 1990-2020, Atmos. Environ., 45, 147-154, doi:10.1016/j.atmosenv.2010.09.034, 2011b.

Li, M., Zhang, Q., Streets, D. G., He, K. B., Cheng, Y. F., Emmons, L. K., Huo, H., Kang, S. C., Lu, Z., Shao, M., Su, H., Yu, X., and Zhang, Y.: Mapping Asian anthropogenic emissions of nonmethane volatile organic compounds to multiple chemical mechanisms, Atmos. Chem. Phys., 14, 5617-5638, doi:10.5194/acp14-5617-2014, 2014.

Liu, Y., Shao, M., Zhang, J., Fu, L. L., and Lu, S. H.: Distributions and source apportionment of ambient volatile organic compounds in Beijing city, China, J. Environ. Sci. Health Part A-Toxic/Hazard. Subst. Environ. Eng., 40, 1843-1860, doi:10.1080/10934520500182842, 2005.

Liu, Y., Shao, M., Fu, L. L., Lu, S. H., Zeng, L. M., and Tang, D. G.: Source profiles of volatile organic compounds (VOCs) measured in China: Part I, Atmos. Environ., 42, 6247-6260, doi:10.1016/j.atmosenv.2008.01.070, 2008.

Liu, Y., Shao, M., Kuster, W. C., Goldan, P. D., Li, X. H., Lu, S. H., and De Gouw, J. A.: Source Identification of Reactive Hydrocarbons and Oxygenated VOCs in the Summertime in Beijing, Environ. Sci. Technol., 43, 75-81, doi:10.1021/es801716n, 2009a.

Liu, J. F., Mu, Y. J., Zhang, Y. J., Zhang, Z. M., Wang, X. K., Liu, Y. J., and Sun, Z. Q.: Atmospheric levels of BTEX compounds during the 2008 Olympic Games in the urban area of Beijing, Sci. Total Environ., 408, 109-116, doi:10.1016/j.scitotenv.2009.09.026, 2009b.

Liu, Z., Wang, Y. H., Vrekoussis, M., Richter, A., Wittrock, F., Burrows, J. P., Shao, M., Chang, C. C., Liu, S. C., Wang, H. L., and Chen, C. H.: Exploring the missing source of glyoxal (CHOCHO) over China, Geophys. Res. Lett, 39, L10812, doi:10.1029/2012g1051645, 2012.

Lu, K. D., Hofzumahaus, A., Holland, F., Bohn, B., Brauers, T., Fuchs, H., Hu, M., Häseler, R., Kita, K., Kondo, Y., Li, X., Lou, S. R., Oebel, A., Shao, M., Zeng, L. M., Wahner, A., Zhu, T., 
Zhang, Y. H., and Rohrer, F.: Missing $\mathrm{OH}$ source in a suburban environment near Beijing: observed and modelled $\mathrm{OH}$ and $\mathrm{HO}_{2}$ concentrations in summer 2006, Atmos. Chem. Phys., 13, 10571080, doi:10.5194/acp-13-1057-2013, 2013.

Lu, S., Liu, Y., Shao, M., and Huang, S.: Chemical speciation and anthropogenic sources of ambient volatile organic compounds (VOCs) during summer in Beijing, 2004, Frontiers of Environmental Science \& Engineering in China, 1, 147-152, doi:10.1007/s11783-007-0026-0, 2007.

McKeen, S. A., Trainer, M., Hsie, E. Y., Tallamraju, R. K., and Liu, S. C.: On the Indirect Determination of Atmospheric OH Radical Concentrations From Reactive Hydrocarbon Measurements, J. Geophys. Res., 95, 7493-7500, doi:10.1029/JD095iD06p07493, 1990.

Parrish, D. D.: Critical evaluation of US on-road vehicle emission inventories, Atmos. Environ., 40, 2288-2300, doi:10.1016/j.atmosenv.2005.11.033, 2006.

Shao, M., Wang, B., Lu, S. H., Yuan, B., and Wang, M.: Effects of Beijing Olympics Control Measures on Reducing Reactive Hydrocarbon Species, Environ. Sci. Technol., 45, 514-519, doi:10.1021/es102357t, 2011.

Simpson, I. J., Sulbaek Andersen, M. P., Meinardi, S., Bruhwiler, L., Blake, N. J., Helmig, D., Rowland, F. S., and Blake, D. R.: Long-term decline of global atmospheric ethane concentrations and implications for methane, Nature, 488, 490-494, doi:10.1038/nature11342, 2012.

Song, Y., Shao, M., Liu, Y., Lu, S. H., Kuster, W., Goldan, P., and Xie, S. D.: Source apportionment of ambient volatile organic compounds in Beijing, Environ. Sci. Technol., 41, 4348-4353, doi:10.1021/es0625982, 2007.

Su, J., Shao, M., Lu, S., and Xie, Y.: Non-methane volatile organic compound emission inventories in Beijing during Olympic Games 2008, Atmos. Environ., 45, 7046-7052, doi:10.1016/j.atmosenv.2011.09.067, 2011.

Tang, X., Zhu, J., Wang, Z. F., and Gbaguidi, A.: Improvement of ozone forecast over Beijing based on ensemble Kalman filter with simultaneous adjustment of initial conditions and emissions, Atmos. Chem. Phys., 11, 12901-12916, doi:10.5194/acp11-12901-2011, 2011.

von Schneidemesser, E., Vieno, M., and Monks, P. S.: The changing oxidizing environment in London-trends in ozone precursors and their contribution to ozone production, Atmos. Chem. Phys. Discuss., 14, 1287-1316, doi:10.5194/acpd-14-1287-2014, 2014.

Wang, B., Shao, M., Lu, S. H., Yuan, B., Zhao, Y., Wang, M., Zhang, S. Q., and $\mathrm{Wu}, \mathrm{D}$.: Variation of ambient non-methane hydrocarbons in Beijing city in summer 2008, Atmos. Chem. Phys., 10, 5911-5923, doi:10.5194/acp-10-5911-2010, 2010a.

Wang, H., Fu, L., Zhou, Y., Du, X., and Ge, W.: Trends in vehicular emissions in China's mega cities from 1995 to 2005, Environ. Pollut., 158, 394-400, doi:10.1016/j.envpol.2009.09.002, $2010 \mathrm{~b}$.

Wang, J. L., Din, G. Z., and Chan, C. C.: Validation of a laboratory-constructed automated gas chromatograph for the measurement of ozone precursors through comparison with a commercial analogy, J. Chromatogr. A, 1027, 11-18, doi:10.1016/j.chroma.2003.08.099, 2004

Wang, M., Shao, M., Chen, W., Yuan, B., Lu, S., Zhang, Q., Zeng, L., and Wang, Q.: A temporally and spatially resolved validation of emission inventories by measurements of ambient volatile or- ganic compounds in Beijing, China, Atmos. Chem. Phys., 14, 5871-5891, doi:10.5194/acp-14-1-2014, 2014a.

Wang, M., Zeng, L., Lu, S., Shao, M., Liu, X., Yu, X., Chen, W., Yuan, B., Zhang, Q., Hu, M., and Zhang, Z.: Development and validation of a cryogen-free automatic gas chromatograph system (GC-MS/FID) for online measurements of volatile organic compounds, Anal. Method., 6, 9424-9434, doi:10.1039/C4AY01855A, 2014b.

Wang, S. X., and Hao, J. M.: Air quality management in China: Issues, challenges, and options, Journal of Environmental Sciences-China, 24, 2-13, doi:10.1016/s1001-0742(11)60724-9, 2012.

Wang, T., Wei, X. L., Ding, A. J., Poon, C. N., Lam, K. S., Li, Y. S., Chan, L. Y., and Anson, M.: Increasing surface ozone concentrations in the background atmosphere of Southern China, 19942007, Atmos. Chem. Phys., 9, 6216-6226, 2009,

http://www.atmos-chem-phys.net/9/6216/2009/.

Wang, Y. S., Ren, X. Y., Ji, D. S., Zhang, J. Q., Sun, J., and Wu, F. $\mathrm{K}$.: Characterization of volatile organic compounds in the urban area of Beijing from 2000 to 2007, J. Environ. Sci.-China, 24, 95-101, doi:10.1016/s1001-0742(11)60732-8, 2012.

Warneke, C., de Gouw, J. A., Holloway, J. S., Peischl, J., Ryerson, T. B., Atlas, E., Blake, D., Trainer, M., and Parrish, D. D.: Multiyear trends in volatile organic compounds in Los Angeles, California: Five decades of decreasing emissions, J. Geophys. Res.-Atmos. 117, D00V17, doi:10.1029/2012jd017899, 2012.

Wei, W., Wang, S. X., Chatani, S., Klimont, Z., Cofala, J., and Hao, J. M.: Emission and speciation of non-methane volatile organic compounds from anthropogenic sources in China, Atmos. Environ., 42, 4976-4988, doi:10.1016/j.atmosenv.2008.02.044, 2008.

Wei, W., Wang, S., Hao, J., and Cheng, S.: Projection of anthropogenic volatile organic compounds (VOCs) emissions in China for the period 2010-2020, Atmos. Environ., 45, 6863-6871, doi:10.1016/j.atmosenv.2011.01.013, 2011.

Wei, W., Cheng, S., Li, G., Wang, G., and Wang, H.: Characteristics of volatile organic compounds (VOCs) emitted from a petroleum refinery in Beijing, China, Atmos. Environ., 89, 358366, doi:10.1016/j.atmosenv.2014.01.038, 2014.

Wu, Y., Wang, R. J., Zhou, Y., Lin, B. H., Fu, L. X., He, K. B., and Hao, J. M.: On-Road Vehicle Emission Control in Beijing: Past, Present, and Future, Environ. Sci. Technol., 45, 147-153, doi:10.1021/es1014289, 2011.

Xie, X., Shao, M., Liu, Y., Lu, S. H., Chang, C. C., and Chen, Z. M.: Estimate of initial isoprene contribution to ozone formation potential in Beijing, China, Atmos. Environ., 42, 6000-6010, doi:10.1016/j.atmosenv.2008.03.035, 2008.

Yuan, B., Shao, M., Lu, S. H., and Wang, B.: Source profiles of volatile organic compounds associated with solvent use in Beijing, China, Atmos. Environ., 44, 1919-1926, doi:10.1016/j.atmosenv.2010.02.014, 2010.

Yuan, B., Shao, M., de Gouw, J., Parrish, D. D., Lu, S., Wang, M., Zeng, L., Zhang, Q., Song, Y., Zhang, J., and Hu, M. Volatile organic compounds (VOCs) in urban air: How chemistry affects the interpretation of positive matrix factorization (PMF) analysis, J. Geophys. Res.-Atmos., 117, D24302, doi:10.1029/2012jd018236, 2012.

Zhang, Q., Streets, D. G., Carmichael, G. R., He, K. B., Huo, H., Kannari, A., Klimont, Z., Park, I. S., Reddy, S., Fu, J. S., Chen, D., Duan, L., Lei, Y., Wang, L. T., and Yao, Z. L.: Asian emis- 
sions in 2006 for the NASA INTEX-B mission, Atmos. Chem. Phys., 9, 5131-5153, doi:10.5194/acp-9-5131-2009, 2009.

Zhang, Q., Yuan, B., Shao, M., Wang, X., Lu, S., Lu, K., Wang, M., Chen, L., Chang, C., and Liu, S.: Variations of ground-level $\mathrm{O}_{3}$ and its precursors in Beijing in summertime between 2005 and 2011, Atmos. Chem. Phys., 14, 6089-6101, doi:10.5194/acp-146089-2014, 2014.
Zhang, Y. L., Wang, X. M., Zhang, Z., Lu, S. J., Shao, M., Lee, F. S. C., and Yu, J. Z.: Species profiles and normalized reactivity of volatile organic compounds from gasoline evaporation in China, Atmos. Environ., 79, 110-118, doi:10.1016/j.atmosenv.2013.06.029, 2013.

Zhao, B., Wang, S. X., Liu, H., Xu, J. Y., Fu, K., Klimont, Z., Hao, J. M., He, K. B., Cofala, J., and Amann, M.: $\mathrm{NO}_{\mathrm{x}}$ emissions in China: historical trends and future perspectives, Atmos. Chem. Phys., 13, 9869-9897, doi:10.5194/acp-13-9869-2013, 2013. 